\title{
A INDUÇÃO TRIBUTÁRIA COMO MEIO DE CONSTRUÇÃO DE UMA ADMINISTRAÇÃO TRIBUTÁRIA EFICIENTE
}

\author{
TAX INDUCTION AS A MEANS OF CONSTRUCTION OF AN EFFICIENT TAX \\ ADMINISTRATION
}

\section{LA INDUCCIÓN TRIBUTARIA COMO MEDIO DE CONSTRUCCIÓN DE UNA ADMINISTRACIÓN TRIBUTARIA EFICIENTE}

\begin{abstract}
Maria Lírida Calou de ARAújo e Mendonça Doutora em Direito pela Universidade Federal de Pernambuco (UFPE). Professora da Pós-graduação strictu sensu em Direito Constitucional pela Universidade de Fortaleza (UNIFOR). Coordenadora e professora do curso de pósgraduação lato sensu em Direito e Processo Tributários pela UNIFOR, do curso de graduação em Direito pela UNIFOR e no Centro Universitário Católica de Quixadá (UNICATÓLICA). (Fortaleza, Ceará, Brasil). http:/ / lattes.cnpq.br/8379193041530131 / http:/ /orcid.org/0000-0001-5710-7499 / Liridacalou@unifor.br

ARnaldo Coelho da SiLVA Filho Mestrando em Direito Constitucional Público e Teoria Política, pela Universidade de Fortaleza (UNIFOR). Especialista em Direito e Processo Tributários pela UNIFOR. (Fortaleza, Ceará, Brasil). http://lattes.cnpq.br/0386267735618840 / http://orcid.org/0000-0002-4114-1040 / arnaldo.csf@gmail.com
\end{abstract}

\begin{abstract}
RESUMO
O presente trabalho trata da indução tributária como concretização de uma Administração Tributária eficiente. Através de um estudo bibliográfico e da aplicação da dedução lógica, percebeu-se que a Administração Tributária eficiente deve focar na diminuição dos custos administrativos e na maior certeza do cumprimento dos fins da legislação tributária. O lançamento por homologação cumpre estes requisitos. Percebeu-se que a transferência dos custos administrativos majora as obrigações do contribuinte, podendo induzi-lo ao descumprimento da legislação. Também se notou que uma Administração Tributária eficiente é focada não apenas na diminuição de custos administrativos em aspecto quantitativo, mas também é um aspecto probabilístico de certeza. Para tanto, a construção de um ideal de Administração Tributária pautada na confiança dos contribuintes se impõe para o cumprimento dos fins de arrecadação.
\end{abstract}

Palavras-chave: Administração Pública; Custos Administrativos; Custos de Conformidade; Eficiência; Indução Tributária.

\begin{abstract}
This paper deals with tax induction as an effective tax administration. Through a bibliographic study and the application of the logical deduction, it was noticed that the efficient Tax Administration should focus on reducing administrative costs and on a greater certainty of compliance with the purposes of the tax legislation. The release by homologation fulfills these requirements. It has been realized that the transference of administrative costs increases the taxpayer's obligations and may lead to non-compliance with the legislation. It has also been noted that an efficient Tax Administration is focused not only on reducing administrative costs in quantitative terms, but it is also a probabilistic aspect of certainty. To do so, the construction of an ideal of Tax Administration based on taxpayers' trust is required for the fulfillment of collection purposes.
\end{abstract}

Keywords: Public Administration; Administrative costs; Conformity costs; Efficiency; Tax Induction. 

ADMINISTRAÇÃO TRIBUTÁRIA EFICIENTE

MARIa Lírida CALOU de ARAúJo E MENDONÇA ARNALDO COELHO dA SilVA FiLHO

\section{RESUMEN}

El presente trabajo trata de la inducción tributaria como concreción de una Administración Tributaria eficiente. A través de un estudio bibliográfico y de la aplicación de la deducción lógica, se percibió que la Administración Tributaria eficiente debe enfocarse en la disminución de los costos administrativos y en la mayor certeza del cumplimiento de los fines de la legislación tributaria. El lanzamiento por homologación cumple estos requisitos. Se percibió que la transferencia de los costos administrativos incrementa las obligaciones del contribuyente, pudiendo inducir al incumplimiento de la legislación. También se notó que una Administración Tributaria eficiente se enfoca no sólo en la disminución de costos administrativos en aspecto cuantitativo, pero también es un aspecto probabilístico de certeza. Para ello, la construcción de un ideal de Administración Tributaria pautada en la confianza de los contribuyentes se impone para el cumplimiento de los fines de recaudación.

Palabras clave: Administración Pública; Costos administrativos; Costos de Conformidad; Eficiencia; Inducción Tributaria.

\section{SUMÁRIO}

INTRODUÇÃO; 1 EFICIÊNCIA ADMINISTRATIVA, ADMINISTRAÇÃO TRIBUTÁRIA E TRANSFERÊNCIA DE CUSTOS ADMINISTRATIVOS; 2 INDUÇÃO TRIBUTÁRIA NO LANÇAMENTO POR HOMOLOGAÇÃO, CONSEQUÊNCIA DA TRANSFERÊNCIA DOS CUSTOS ADMINISTRATIVOS E PENALIDADES TRIBUTÁRIAS; 3 NOVO IDEAL DE ADMINISTRAÇÃO TRIBUTÁRIA EFICIENTE PELO CRITÉRIO DA CERTEZA E TAX COMPLIANCE; CONCLUSÃO; REFERÊNCIAS.

\section{INTRODUÇÃO}

A eficiência, inserida pela Emenda Constitucional $n^{\circ} 19$ de 04 de junho de 1998, no caput do art. 37 da Constituição Federal/88, positivou contorno já paradigmático no Direito Administrativo e na Administração Pública em relação aos seus servidores e administrados. Falase em eficiência em sentido jurídico, com respeito a todo o ordenamento jurídico e à constante legitimação frente aos cidadãos, que vise atuação menos custosa e mais vantajosa para a Administração Pública, focada nos fins escolhidos pelo legislador. Conceitos de outras ciências serão meramente auxiliares na concretização da definição de eficiência, não sendo com eles confundido. Portanto, a eficiência da Administração Pública que se adota toma a juridicidade como parâmetro.

Uma Administração Tributária eficiente é a que se vale de menos custos administrativos e maior certeza no cumprimento dos fins de arrecadação. A transferência dos custos administrativos para o contribuinte, através de métodos de autofiscalização e arrecadação espontânea dos seus tributos, atende o requisito da eficiência. Para tanto, a indução deverá ser vantajosa e percebida em relação de custo/benefício. O lançamento por homologação é espécie de transferência do custo administrativo para o contribuinte. Contudo, o repasse da responsabilidade da obrigação de verificar o fato gerador, calcular o montante do tributo e 
pagá-lo não garante o correto respeito à legislação tributária. As penalidades tributárias parecem não induzir adequadamente o comportamento requerido pela lei. 0 descumprimento obrigaria a Administração Tributária a fiscalizar a atuação do contribuinte, retomando os custos administrativos, na contramão da eficiência.

Surge o questionamento: em atenção à concepção de eficiência da Administração Tributária, regulada pelo princípio da juridicidade administrativa, sendo concretizada pela transferência de custos administrativos através do lançamento por homologação, é possível garantir maior cumprimento à legislação tributária por parte do contribuinte?

Visando responder este questionamento, objetiva-se, em geral, construir um ideal de Administração Tributária que adote a eficiência pelo parâmetro da juridicidade administrativa. Focada em menos custos e mais certeza na arrecadação, contemplando a confiança do contribuinte e induzindo-o a cumprir a legislação tributária quando do lançamento por homologação.

Para tanto, o trabalho é dividido em três partes. Na primeira, introduz-se a eficiência por suas características no ordenamento, teorias de relevância, critérios de aferição e aplicabilidade à Administração Tributária. Defende-se acepção de eficiência focada na diminuição de custos administrativos pela transferência e maior certeza da arrecadação tributária. Na segunda, investiga-se a doutrina sobre a indução tributária e a consequência da transferência de custos administrativos para o contribuinte quanto ao cumprimento da legislação tributária, quando obrigado a realizar o lançamento por homologação. Na terceira, busca-se responder o questionamento do trabalho. Apresenta-se que a questão do cumprimento da legislação tributária é tema de pesquisas internacionais sobre tax compliance. Estes estudos defendem proposições focadas na melhoria da confiança do contribuinte na Administração Tributária, induzindo-o ao cumprimento espontâneo da legislação tributária.

A pesquisa é bibliográfica e com atenção a pesquisas empíricas internacionais já realizadas. Fundamenta-se em livros, artigos, periódicos específicos sobre o tema e publicações de pesquisas. 0 método é lógico-dedutivo, partindo-se, portanto, do geral para o específico. 


\section{EFICIÊNCIA ADMINISTRATIVA, ADMINISTRAÇÃO TRIBUTÁRIA E TRANSFERÊNCIA DE CUSTOS ADMINISTRATIVOS}

O texto expresso de eficiência foi inserido no caput do art. 37 da CF/88, através da Emenda Constitucional $n^{\circ} 19 / 98$, como princípio a ser observado pelos Poderes da União, dos Estados, do Distrito Federal e dos Municípios. Mas o contexto da eficiência já estava presente no Direito Administrativo brasileiro. $\mathrm{O}$ art. 74 , $\mathrm{II}^{1}$, e o art. $144, \S 7^{\circ 2}$, bem como a Lei $\mathrm{n}^{\circ} 8.987$, de 13 de fevereiro de 1995, já continham a expressão “eficiência” em sua redação, mesmo antes da alteração constitucional.

A inclusão do termo na Constituição Federal foi tema de discussões dos doutrinadores administrativos brasileiros. Alguns a favor da inclusão, entendendo se tratar de marco para uma nova Administração Pública, focada mais nos resultados externos da sua atuação. Outros, contra a inclusão, apelando para previsões de retrocessos da Ordem Constitucional de 1988 e rompimento com o Estado de Direito. Contudo, o agir eficiente sempre foi a regra para a Administração Pública, sendo a inclusão do termo redundante e desnecessária. Pelo menos, restou incluído o termo "eficiência” e não "qualidade dos serviços públicos”, como presente no projeto da emenda constitucional ${ }^{3}$.

O significado de "eficiência" dependerá do enfoque que se adota. A eficiência do art. 37 da CF/88 é norma jurídica, não se confundindo com a eficiência das ciências econômicas ou da administração. Tais conceitos podem, contudo, auxiliar na concretização de um conceito de eficiência jurídica ${ }^{4}$. Em linguagem comum, confunde-se com o conceito de eficácia ${ }^{5}$. Essa

\footnotetext{
${ }^{1}$ Art. 74. Os Poderes Legislativo, Executivo e Judiciário manterão, de forma integrada, sistema de controle interno com a finalidade de: II - comprovar a legalidade e avaliar os resultados, quanto à eficácia e eficiência, da gestão orçamentária, financeira e patrimonial nos órgãos e entidades da administração federal, bem como da aplicação de recursos públicos por entidades de direito privado;

BRASIL. Constituição Federal. República Federativa do Brasil, Brasília, 5 out. 1988. Disponível em: <http://www.planalto.gov.br/ccivil_03/constituicao/constituicao.htm>. Acesso em: 10 jun. 2017.

2 Art. 144. A segurança pública, dever do Estado, direito e responsabilidade de todos, é exercida para a preservação da ordem pública e da incolumidade das pessoas e do patrimônio, através dos seguintes órgãos: $\S 7^{\circ} \mathrm{A}$ lei disciplinará a organização e o funcionamento dos órgãos responsáveis pela segurança pública, de maneira a garantir a eficiência de suas atividades.

BRASIL. Constituição Federal. República Federativa do Brasil, Brasília, 5 out. 1988. Disponível em: <http://www.planalto.gov.br/ccivil_03/constituicao/constituicao.htm>. Acesso em: 10 jun. 2017.

3 MODESTO, Paulo. Notas para um Debate sobre o Princípio Constitucional da Eficiência. Revista Interesse Público, São Paulo, Ed. Notadez, n. 7, p. 65-75, 2000.

4 AMARAL, Antônio Carlos Cintra do. O princípio da eficiência no direito administrativo. Revista Eletrônica sobre a Reforma do Estado, Salvador, n. 5, mar./abr./maio 2006. Disponível em:
} 

ADMINISTRAÇÃO TRIBUTÁRIA EFICIENTE

afirmação só faz sentido quando se compreende a eficiência no mesmo sentido que das ciências da administração ${ }^{6}$. O que se aceita é a eficácia como um pressuposto para a eficiência, mas não como sinônimo, sendo este o melhor entendimento. Posicionamento contrário afasta a juridicidade da norma do art. 37. Como norma jurídica, o sentido de eficiência positivada no texto constitucional não se confunde com eficácia.

A doutrina administrativa apresenta diversas teorias para o princípio da eficiência. Visão difundida na doutrina brasileira é a da eficiência como principio constitucional, especialmente após a EC $n^{\circ} 19 / 1998^{7}$. O agir eficiente pode ser considerado um dever do administrador, pois além de imposto pela lei (e desde 1998 também pela Constituição), o é também pela moral administrativa e exigido pelo interesse público ${ }^{8}$. Mas também pode ser considerado postulado que estrutura a aplicação de regras e princípios?

Pode, ainda, ser considerada como decorrência do princípio da legalidade, que sempre requer atuação ótima do administrador, mesmo nos casos de discricionariedade ${ }^{10}$. Pode ser elemento de Direito Fundamental à Boa Administração Pública, como direito subjetivo público à boa administração eficiente e eficaz ${ }^{11}$. Parece que cada uma destas teorias apresenta pontos de intersecção entre si, mas sem uma definição prática e lógica da eficiência. Denomina-se “princípio da eficiência” sem sequer haver maiores discussões sobre sua aplicabilidade. Não é este o conteúdo da eficiência que se busca.

A visão legalista do pensamento de Montesquieu deu causa à crise da lei e da confiança da legalidade. Como razões específicas, cita-se, em primeira, a inflação legislativa, banalizando-

\footnotetext{
<http://www.direitodoestado.com/revista/RERE-5-MAR\%C70-2006-CARLOS\%20CINTRA.pdf>. Acesso em: 10 jun. 2017.

${ }_{5}^{5}$ Para as Ciências da Administração, eficácia é relacionada aos fins buscados. Já eficiência é relacionada com os meios. Quando se analisa a eficiência em linguagem comum, erra-se ao confundir os conceitos. A melhor análise é a jurídica, no qual eficiência e eficácia não podem ser confundidas.

6 COSTÓDIO FILHO, Ubirajará. A Emenda Constitucional n. ${ }^{\circ} 19 / 98$ e o princípio da eficiência na Administração Pública. Revista de Direito Constitucional e Internacional, Cadernos de Direito Constitucional e Ciência Política, São Paulo, v. 27, p. 209-217, abr./jun. 1999.

7 MIRAGEM, Bruno. A nova Administração Pública e o direito administrativo. São Paulo: Revista dos Tribunais, 2011.

${ }^{8}$ MEIRELLES, Hely L. Direito Administrativo Brasileiro. 36. ed. São Paulo: Malheiros, 2010.

${ }^{9}$ AVILA, Humberto. Moralidade, Razoabilidade e Eficiência na Atividade Administrativa. Revista Eletrônica de Direito do Estado, Salvador, Instituto de Direito Público da Bahia, n. 4, out./nov./dez. 2005. Disponível em: <http://www.direitodoestado.com.br/artigo/humberto-avila/moralidade-razoabilidade-eeficiencia-na-atividade-administrativa >. Acesso em: 23 nov. 2016.

${ }^{10}$ MELLO, Celso Antônio Bandeira de. Discricionariedade e Controle Jurisidicional. São Paulo: Malheiros, 1998.

11 FREITAS, Juarez. Discricionariedade Administrativa e o Direito Fundamental à Boa Administração Pública. São Paulo: Malheiros, 2007.
} 

ADMINISTRAÇÃO TRIBUTÁRIA EFICIENTE

se a lei e fragilizando os ideais de segurança e certeza. Em segunda, a perda de importância da lei, percebendo-se a mesma como insuficiente para garantir justiça e liberdade. Em terceira, o abandono da lei como manifestação maior da vontade geral do povo, com a ascensão do constitucionalismo. Em quarta, a criação de diversos atos infralegais que servem de fundamento à atuação administrativa. Por fim, a quinta razão se daria pela existência de pressão política do Executivo ao Legislativo. As razões acima resultaram em desprestígio da lei e do próprio legislador, dando-se o fracasso da lei estatal como projeto jurídico-politico ${ }^{12}$.

Revisou-se a importância da lei como fundamento único de atuação da Administração Pública. A abertura para um modelo baseado em princípios e regras, com a lei posta como mais um fundamento para a atuação da Administração Pública desenvolveu espaço para se falar em princípio da juridicidade. Em Direito Administrativo, é o que se chamou de princípio da juridicidade administrativa ${ }^{13}$.

O conceito de eficiência que se defende é o que atende a finalidade do interesse público específico previsto na lei e escolhido pelo legislador. Regula-se pela juridicidade - não apenas a lei imposta, mas a legitimada pelo consenso democrático. 0 ato legislativo não é apenas legal, mas também legítimo. A eficiência que se busca não é somente fim axiológico a ser perseguido, é requisito mínimo de escolha do conteúdo jurídico que deve ser satisfeito para que o objeto do ato administrativo atenda ao interesse público específico definido pelo legislador. É dever de bem administrar, limitado pela razoabilidade e pela realidade ${ }^{14}$.

É dever implícito da própria Administração Pública, sendo sua positivação redundante e desnecessária ${ }^{15}$, e não apenas em relação à prestação dos seus serviços públicos, mas também em sua própria estrutura. Uma Administração Pública voltada para a fiscalização e arrecadação de tributos (Administração Tributária) deve ser eficiente em sua forma de atuação, não se confundindo com diminuição de menos $^{16}$. Ou seja, atende a finalidade do interesse público em melhor arrecadar recursos tributários, mas melhor arrecadar não é arrecadar mais.

\footnotetext{
12 BINENBOJM, Gustavo. Uma Teoria do Direito Administrativo. 2. ed. Rio de Janeiro: Renovar, 2008.

13 BINENBOJM, Gustavo. Uma Teoria do Direito Administrativo. 2. ed. Rio de Janeiro: Renovar, 2008.

14 MOREIRA NETO, Diogo de Figueiredo. Legitimidade e Discricionariedade: novas reflexões sobre os limites e controle da discricionariedade. 3. ed. Rio de Janeiro: Forense, 1998.

${ }^{15}$ MODESTO, Paulo. Notas para um Debate sobre o Princípio Constitucional da Eficiência. Revista Interesse Público, São Paulo, Ed. Notadez, n. 7, p. 65-75, 2000.

${ }^{16}$ LIMA, Leandro Manoel Matias de. A aplicação do dever de eficiência à Administração Pública Tributária e sua relação com a Moral Tributária dos contribuintes. Revista Digital de Direito Administrativo, v. 2, n. 1, p. 273-292, 2015.
} 

ADMINISTRAÇÃO TRIBUTÁRIÁ EFICIENTE

MARIa Lírida CALOU de ARAúJo E MENDONÇA ARNALDO COELHO dA SilVA FiLHO

O critério de aferição do dever de eficiência administrativa não pode ser o mero critério quantitativo monetário. O dever da eficiência é pautado em promover o fim escolhido pelo legislador de modo satisfatório. O fim da Administração Tributária é melhor arrecadar recursos tributários e a melhor análise deste critério é pela proporcionalidade ${ }^{17}$. Para análise da eficiência, importa a atenção à adequação - análise empírica de vários meios adequados a um fim. Avalia-se pelos aspectos quantitativos (intensidade), qualitativos (qualidade) e probabilísticos (certeza). Importa também a proporcionalidade em sentido estrito - se as vantagens que promove são maiores que as desvantagens que causa. A melhor escolha é aquela vantajosa, com adequação minimamente intensa (menos custosa), certa (provável) e que cumpra o fim atribuído à Administração Pública ${ }^{18}$. Portanto, a atuação eficiente da Administração Tributária não deve observar o critério meramente quantitativo, visando tão somente a diminuição de custos administrativos, mas também critérios de qualidade e certeza desta arrecadação.

Desta forma, a escolha da atuação da Administração Tributária para a arrecadação de tributos deve considerar todos os critérios supramencionados. Embora o critério quantitativo não seja o único a ser considerado, é o primeiro que se percebe em análise de custo/benefício. A Administração Tributária incorre em custos administrativos para seu funcionamento operacional de fiscalização, arrecadação e cobrança de $\operatorname{tributos}^{19}$ e o primeiro critério que se observa em uma atuação eficiente é o da diminuição dos custos administrativos.

\footnotetext{
${ }^{17}$ A proporcionalidade aqui adotada se divide em adequação, necessidade e proporcionalidade em sentido estrito. In: AVILA, Humberto. Moralidade, Razoabilidade e Eficiência na Atividade Administrativa. Revista Eletrônica de Direito do Estado, Salvador, Instituto de Direito Público da Bahia, n. 4, out./nov./dez. 2005. Disponível em: <http://www.direitodoestado.com.br/artigo/humberto-avila/moralidaderazoabilidade-e-eficiencia-na-atividade-administrativa>. Acesso em: 23 nov. 2016.

Com o mesmo entendimento, mas outra nomenclatura, é a razoabilidade em sentido externo. In: BARROSO, Luís Roberto. Interpretação e Aplicação da Constituição. 5. ed. São Paulo: Saraiva, 2003. MOREIRA NETO, Diogo de Figueiredo Moreira; GARCIA, Flavio Amaral. Revista Eletrônica de Direito Administrativo Econômico (REDAE), Salvador, Instituto Brasileiro de Direito Público, n. 28, nov./dez./jan. 2011/2012. Disponível em: <http://www.direitodoestado.com/revista/REDAE-28NOVEMBRO-2011DIOGO-FIGUEIREDO-FLAVIO-GARCIA.pdf>. Acesso em: 16 dez. 2016.

A preocupação com a explicação por manutenção de coerência teórica é a partir da concepção da eficiência como aquela que atenda ao interesse público específico estabelecido pelo legislador como finalidade de atuação administrativa.

18 AVILA, Humberto. Moralidade, Razoabilidade e Eficiência na Atividade Administrativa. Revista Eletrônica de Direito do Estado, Salvador, Instituto de Direito Público da Bahia, n. 4, out./nov./dez. 2005. Disponível em: <http://www.direitodoestado.com.br/artigo/humberto-avila/moralidaderazoabilidade-e-eficiencia-na-atividade-administrativa>. Acesso em: 23 nov. 2016.

${ }^{19}$ BERTOLUCCI, Aldo Vincenzo. Uma contribuição ao estudo da incidência dos custos de conformidade às leis e disposições tributárias: um panorama mundial e pesquisa dos custos das companhias de capital
} 
A diminuição nos custos para fiscalizar, arrecadar e cobrar tributos reflete na quantidade de recursos disponíveis para utilização em outras finalidades. Permite que se atenda uma maior quantidade de finalidades específicas previstas pelo legislador como interesse público. Diminuir os custos administrativos de arrecadação, apesar de não resultar necessariamente em um maior recebimento de recursos, resulta em maior disponibilidade financeira. Criaram-se instrumentos jurídicos com o objetivo de se adequar os custos administrativos com a finalidade que se visa alcançar, especialmente após a positivação da eficiência no art. $37 \mathrm{da} C F / 88^{20}$.

Além do custo da Administração Tributária para fiscalizar, arrecadar e cobrar, existe o custo do contribuinte para se adequar à legislação tributária. É o custo de conformidade. Pode ser dividido em três: i) monetários diretos, na contratação de pessoa física ou jurídica para realização das atividades conexas ao pagamento do tributo; ii) temporais, que corresponde ao tempo necessário para cumprir as obrigações acessórias ao pagamento do tributo; e iii) psicológicos, relacionados com as condições de estresse, ansiedade e incerteza do contribuinte com o cumprimento das obrigações acessórias ${ }^{21}$.

A Administração Tributária, visando atender maior número de finalidades e agir de forma eficiente, desenvolve meios de transferir o custo administrativo para o contribuinte. Quando se transfere para o contribuinte o custo administrativo de apurar o tributo, também se cria outro custo de conformidade, além do pagamento do tributo com seus acréscimos. 0 contribuinte suporta o custo que a Administração Tributária incorreria para fiscalização e arrecadação. Esta obrigação pode vir acompanhada de benefício ao contribuinte, como a denúncia espontânea ${ }^{22}$, mas não é regra.

aberto no Brasil. São Paulo: FEA/USP, 2001. Dissertação (Mestrado) - Faculdade de Economia e Administração, Universidade de São Paulo, São Paulo, 2001.

${ }^{20}$ MORAIS, Dalton Santos. Os custos da atividade administrativa e o princípio da eficiência. Revista dos Tribunais, v. 837, p. 79-105, jul. 2005.

${ }^{21}$ BERTOLUCCI, Aldo Vincenzo. Uma contribuição ao estudo da incidência dos custos de conformidade às leis e disposições tributárias: um panorama mundial e pesquisa dos custos das companhias de capital aberto no Brasil. São Paulo: USP, 2001. Dissertação (Mestrado) - Faculdade de Economia e Administração, Universidade de São Paulo, São Paulo, 2001.

${ }^{22}$ Art. 138. A responsabilidade é excluída pela denúncia espontânea da infração, acompanhada, se for o caso, do pagamento do tributo devido e dos juros de mora, ou do depósito da importância arbitrada pela autoridade administrativa, quando o montante do tributo dependa de apuração. Parágrafo único. Não se considera espontânea a denúncia apresentada após o início de qualquer procedimento administrativo ou medida de fiscalização, relacionados com a infração.

BRASIL. Lei $n^{\circ} 5.172$, de 25 de outubro de 1966. Dispõe sobre o Sistema Tributário Nacional e institui normas gerais de direito tributário aplicáveis à União, Estados e Municípios. Diário Oficial da República 

ADMINISTRAÇÃO TRIBUTÁRIÁ EFICIENTE

MARIa Lírida CALOU de ARAúJo E MENDONÇA ARNALDO COELHO dA SilVA FiLHO

O custo administrativo de fiscalização é transferido na forma de obrigações acessórias de prestar declarações. A transferência do custo administrativo para o contribuinte cria novo custo de conformidade, que dificulta e é desincentivo ao cumprimento da legislação tributária com rigor ${ }^{23}$. O lançamento por homologação, que é aquele em que o contribuinte é obrigado a verificar o fato gerador, apurar o valor do tributo, prestar a declaração correspondente e realizar o pagamento antecipado (art. 150, $\mathrm{CTN}^{24}$ ) é atuação eficiente (menos custosa, provável de ocorrer e que visa à finalidade da Administração Tributária de arrecadar recursos tributários) que transfere o custo administrativo para o contribuinte, com a consequente criação de novo custo de conformidade.

Existem vantagens de cunho prático no lançamento por homologação para o contribuinte. Pode considerar extinto seu crédito, para fins de pedido de restituição, desde a data do pagamento antecipado e não da data da homologação ${ }^{25}$. Além da garantia de que caso o Fisco não se manifeste em 5 (cinco) anos contados do fato gerador, a declaração apresentada será homologada tacitamente, desde que o contribuinte não tenha agido com comprovado dolo, fraude ou simulação (art. 150, $\$ 4^{\circ}, \mathrm{CTN}^{26}$ ), o que limita o Fisco em exigir tributos que tenham

Federativa do Brasil, Brasília, 27 out. 1966. Disponível em:
<http://www.planalto.gov.br/ccivil_03/leis/L5172Compilado.htm>. Acesso em: 23 nov. 2016.

${ }^{23}$ PLUTARCO, Hugo Mendes; GICO Jr., Ivo Teixeira; VALADÃO, Marcos Aurélio Pereira. O Custo Social das Obrigações Tributárias Acessórias. Economic Analysis of Law Review, v. 3, n. 2, p. 338-353, 2012.

E, ainda, conforme posicionamentos de: VALENTE, Christiano Mendes Wolney. Denúncia espontânea: uma análise econômica da jurisprudência do STJ. Revista Fórum de Direito Tributário, Belo Horizonte, v. 13, n. 74, p. 81-100, mar. 2015.

${ }^{24}$ Art. 150. O lançamento por homologação, que ocorre quanto aos tributos cuja legislação atribua ao sujeito passivo o dever de antecipar o pagamento sem prévio exame da autoridade administrativa, operase pelo ato em que a referida autoridade, tomando conhecimento da atividade assim exercida pelo obrigado, expressamente a homologa.

BRASIL. Lei $\mathrm{n}^{\circ} 5.172$, de 25 de outubro de 1966. Dispõe sobre o Sistema Tributário Nacional e institui normas gerais de direito tributário aplicáveis à União, Estados e Municípios. Diário Oficial da República Federativa do Brasil, Brasília, 27 out. 1966. Disponível em: <http://www.planalto.gov.br/ccivil_03/leis/L5172Compilado.htm>. Acesso em: 23 nov. 2016.

${ }^{25}$ Art. 30 Para efeito de interpretação do inciso I do art. 168 da Lei no 5.172, de 25 de outubro de 1966 Código Tributário Nacional, a extinção do crédito tributário ocorre, no caso de tributo sujeito a lançamento por homologação, no momento do pagamento antecipado de que trata o § 10 do art. 150 da referida Lei.

BRASIL. Lei Complementar $n^{\circ} 118$, de 9 de fevereiro de 2005. Altera e acrescenta dispositivos à Lei no 5.172, de 25 de outubro de 1966 - Código Tributário Nacional, e dispõe sobre a interpretação do inciso I do art. 168 da mesma Lei. Diário Oficial da República Federativa do Brasil, Brasília, 9 fev. 2005. Disponível em: <http://www.planalto.gov.br/ccivil_03/leis/LCP/Lcp118.htm>. Acesso em: 23 nov. 2016.

${ }^{26}$ Art. 150 . (...) $\$ 4^{\circ}$ Se a lei não fixar prazo a homologação, será ele de cinco anos, a contar da ocorrência do fato gerador; expirado esse prazo sem que a Fazenda Pública se tenha pronunciado, considera-se homologado o lançamento e definitivamente extinto o crédito, salvo se comprovada a ocorrência de dolo, fraude ou simulação. 
superado este prazo. Contudo, o encargo resultante da transferência do custo administrativo para o cumprimento da obrigação de prestar declaração supera seu benefício.

Pelo exposto, cabe indagar: a transferência de custos administrativos para o contribuinte, obrigando-o a realizar o lançamento por homologação, onerando seu encargo tributário, pode induzir o contribuinte a agir de forma ilegal? Há garantias que somente a penalidade tributária posterior seja medida eficaz para inibir a prática ilegal? Essas são as perguntas que se pretende responder na parte seguinte.

\section{INDUÇÃO TRIBUTÁRIA NO LANÇAMENTO POR HOMOLOGAÇÃO, CONSEQUÊNCIA DA TRANSFERÊNCIA DOS CUSTOS ADMINISTRATIVOS E PENALIDADES TRIBUTÁRIAS}

Analisado em tópico anterior o conceito de eficiência administrativa regulada pela juridicidade administrativa e o critério de aferição pela proporcionalidade (menos custosa, provável de ocorrer e que vise à finalidade escolhida pelo legislador), concluiu-se que sua manifestação é realizada pela transferência de custos administrativos da Administração Tributária para o contribuinte com o objetivo de arrecadação. O lançamento por homologação é instituto que atende o exposto visando eficiente arrecadação tributária.

A transferência do custo administrativo por este instituto cria novos custos de conformidade para o contribuinte. Há estímulo, portanto, para cumprir legislação tributária tão onerosa? Caso descumpra a legislação, a possibilidade de penalidade posterior é suficiente para inibir este comportamento? A investigação deve ser realizada pela via da indução tributária.

A atuação estatal engloba tanto aquela no setor privado, como a prestação e a regulação do serviço público. É conceito que se reporta ao de atividade econômica em sentido amplo. Entretanto, quando realizada em área de atuação diversa da sua normal (setor privado), adota o nome de intervenção. Atuar é o agir; intervir é o agir em área diversa de sua alçada original $^{27}$. O local da intervenção do Estado na economia é no domínio econômico ${ }^{28}$.

BRASIL. Lei $n^{\circ} 5.172$, de 25 de outubro de 1966. Dispõe sobre o Sistema Tributário Nacional e institui normas gerais de direito tributário aplicáveis à União, Estados e Municípios. Diário Oficial da República Federativa do Brasil, Brasília, 27 out. 1966. Disponível em: <http://www.planalto.gov.br/ccivil_03/leis/L5172Compilado.htm>. Acesso em: 23 nov. 2016.

${ }^{27}$ GRAU, Eros Roberto. A ordem econômica na Constituição de 1988: interpretação e crítica. 12. ed. São Paulo: Malheiros, 2007. 

ADMINISTRAÇÃO TRIBUTÁRIA EFICIENTE

Quando da intervenção econômica, o Estado age de três formas distintas: a) por absorção ou participação; b) por direção; ou c) por indução. Na primeira, atua como se empresário fosse: por absorção, cria monopólio sobre certo bem ou serviço, e por participação, atua no mercado em regime de concorrência com a iniciativa privada. Essa espécie de intervenção é conhecida como direta no domínio econômico, mediante suas sociedades de economia mista e empresas públicas. Na segunda, através de normas de intervenção por direção, dotadas de comandos imperativos, impostas inclusive às empresas estatais em regime de concorrência. Na terceira, por indução, estimulando ou desestimulando condutas. Nas duas últimas a intervenção é indireta sobre o domínio econômico ${ }^{29}$.

Por indução, a atuação estatal toma feição regulatória por meio de normas com caráter persuasivo, que atuam na vontade consciente. A sanção, nesse tipo de normativo, pode possuir faceta de premial ou incentivadora ${ }^{30}$. Objetiva estimular o agente econômico a adotar a conduta desejável. A intervenção deve ser racional e planejada, pois a atuação em um setor pode influenciar outros e utilizar medida isolada de intervenção poderá ter efeitos negativos em outros setores. A situação de equilíbrio sempre será meta visada ${ }^{31}$. A norma de indução não guarda obrigatoriedade de cumprimento, como as normas de direção. 0 sujeito pondera os benefícios e malefícios de praticar seu ato de incidência. Se aderir à norma, restará vinculado a sua prescrição, correspondente ao benefício normativo previsto.

As normas indutoras existem em todo o ordenamento jurídico. Em matéria de tributação, recebem o nome de normas tributárias indutoras. São meios para a obtenção de um fim. Como o Direito Tributário é instrumento que não possui vontade, o fim objetivado é o do sistema político vigente ${ }^{32}$. São as normas que compõem o sistema de direito positivo da Ordem Tributária que concretizam o instrumental do Direito Tributário.

Quanto às normas tributárias, é impossível considerar caráter de diretivo. Não se cogita de conduta dirigida por normas tributárias, se o pressuposto é a liberdade do contribuinte incorrer ou não no fato gerador ${ }^{33}$. Somente praticando-o nascerá a obrigação tributária e a

\footnotetext{
${ }^{28}$ SCHOUERI, Luis Eduardo. Normas Tributárias Indutoras e Intervenção Econômica. Rio de Janeiro: Forense, 2005.

${ }^{29}$ MONCADA, Luis S. Cabral de. Direito Econômico: revista e actualizada. 2. ed. Coimbra: Coimbra, 1988.

30 BOBBIO, Norberto. Da Estrutura à Função: novos estudos de teoria do Direito. Tradução de Daniela Beccaccia Versiani. Barueri: Manole, 2007.

${ }^{31}$ FONSECA, João Bosco Leopoldino da. Direito Econômico. 6. ed. Rio de Janeiro: Forense, 2010.

32 BECKER, Alfredo Augusto. Teoria Geral do Direito Tributário. 5. ed. São Paulo: Noeses, 2010.

33 SCHOUERI, Luis Eduardo. Normas Tributárias Indutoras e Intervenção Econômica. Rio de Janeiro: Forense, 2005.
} 
relação jurídica tributária consequente, podendo se falar em incidência da obrigatoriedade legal de cumprimento ${ }^{34}$. Fosse o contribuinte obrigado a incorrer no fato gerador, estar-se-ia diante de efeito confiscatório da tributação. Caso impossível a prática do fato gerador, por outro lado, sequer poderia se falar em norma tributária.

A norma tributária só poderá possuir o caráter indutor. A indução encontra-se com o Direito Tributário na função extrafiscal dos tributos. A norma indutora pode onerar ou desonerar tributo, a depender do exercício de determinado comportamento. É o exemplo de onerar imposto de importação. É indução negativa, pois não se proíbe fato de importação, porém o Estado pode onerá-la de forma a considerá-la proibitiva ${ }^{35}$.

A identificação da função extrafiscal resulta no reconhecimento do caráter indutor da norma tributária. Sua validade dependerá da atenção aos princípios e regras constitucionais, sendo árdua a tarefa de identificar o efeito indutor das normas, como casos de tratamentos tributários mais complexos, onde o resultado final não é facilmente apresentado ${ }^{36}$.

Não é somente por meio da tributação que haverá a indução. Esta é importante, mas não única. Quando se fala de normas tributárias indutoras, não se está falando de tributos indutores. Afora a tributação extrafiscal, existem mecanismos outros que o Estado pode se valer para induzir o comportamento dos contribuintes. É o caso de normas tributárias indutoras ${ }^{37}$.

Embora a norma do lançamento por homologação não seja daquelas que opte por adotar, distinguindo-se do conceito clássico das normas tributárias indutoras, possui também caráter indutor. Isso porque não se pode obrigar o contribuinte a realizar ou não a previsão legislativa de declarar e pagar antecipadamente o tributo. É certo que a obrigação tributária existirá. O cumprimento da obrigação acessória e da obrigação principal, previstos na norma do lançamento por homologação, por outro lado, dependem exclusivamente da vontade do contribuinte. A sua adoção, portanto, dependerá da indução a qual o contribuinte esteja submetido.

\footnotetext{
${ }^{34}$ FALCÃO, Amílcar de Araújo. Fato Gerador da Obrigação Tributária. 6. ed. Rio de Janeiro: Forense, 1997.

${ }^{35}$ GRAU, Eros Roberto. A ordem econômica na Constituição de 1988: interpretação e crítica. 12. ed. São Paulo: Malheiros, 2007. E, ainda: BECKER, Alfredo Augusto. Teoria Geral do Direito Tributário. 5. ed. São Paulo: Noeses, 2010.

${ }^{36}$ BRANDÃO, Renata Figueirêdo. Incentivo Fiscal Ambiental: parâmetros e limites para sua instituição à luz da Constituição Federal de 1988. São Paulo: USP, 2013. Tese (Doutorado) - Faculdade de Direito da Universidade de São Paulo, São Paulo, 2013.

37 SCHOUERI, Luis Eduardo. Normas Tributárias Indutoras e Intervenção Econômica. Rio de Janeiro: Forense, 2005.
} 

ADMINISTRAÇÃO TRIBUTÁRIA EFICIENTE

0 apresentado fundamenta respostas às questões apresentadas no início desta segunda parte. O lançamento por homologação onera o contribuinte com os custos administrativos originalmente suportados pela Administração Tributária, criando novo custo de conformidade. A obrigação de realizar toda a apuração do tributo e realizar seu pagamento antecipado é custo de conformidade que não pode ser desprezado. Pagar antecipadamente simplesmente para cumprir obrigação legal, sem nenhum desconto em contrapartida, pode não ser vantagem para o contribuinte. O custo temporal do dinheiro é considerado e implica em majoração da carga tributária implícita a qual o contribuinte se encontra submetido. Embora o lançamento por homologação diminua os custos administrativos da Administração Tributária, a questão da certeza do cumprimento da legislação tributária ainda é vacilante. Portanto, em resposta ao primeiro questionamento do final da primeira parte do trabalho, conclui-se que este novo encargo transferido pode majorar o contribuinte a um ponto que, em uma relação custo/benefício superficial, entenda ser mais vantajoso optar pelo não pagamento do tributo ${ }^{38}$.

0 não pagamento implica em duas espécies de penalidade que normalmente são aplicadas em conjunto: a pecuniária (multa punitiva) e a criminal (crimes contra ordem tributária). Não se infere natureza penal da norma tributária pelo diploma em que se encontra inserida. Sempre será jurídica-penal se a sua natureza contemplar possível ofensa ao ordenamento e desde que a associando a uma sanção ${ }^{39}$. No caso da norma tributária, a sanção jurídica punitiva pelo não pagamento possui duplo caráter: repressivo e preventivo. Por um lado, retribui o descumprimento da norma, por outro, visa proteger aquele mandamento legal. É norma de caráter externo (resposta do grupo) e institucionalizada (regulada como outras normas $^{40}$.

É certo que os crimes tributários e as infrações possuem a mesma natureza de norma jurídica, embora diferenciem na qualidade. O crime pune violação à Ordem Tributária e a infração pune descumprimento de normas impostas pelo Direito Tributário ${ }^{41}$. É certo que as duas possuem qualidades distintas em relação à indução do comportamento do contribuinte, conduzindo a análise de sopesamento que considere suas peculiaridades conjuntas.

\footnotetext{
${ }^{38}$ PLUTARCO, Hugo Mendes; GICO Jr., Ivo Teixeira; VALADÃO, Marcos Aurélio Pereira. O Custo Social das Obrigações Tributárias Acessórias. Economic Analysis of Law Review, v. 3, n. 2, p. 338-353, 2012.

39 BECKER, Alfredo Augusto. Teoria Geral do Direito Tributário. 5. ed. São Paulo: Noeses, 2010.

${ }^{40}$ BOBBIO, Norberto. Teoria da Norma Jurídica. Barueri, SP: Edipro, 2001.

${ }^{41}$ BITTENCOURT, Cezar Roberto; MONTEIRO, Luciana de Oliveira. Crimes Contra Ordem Tributária. São Paulo: Saraiva, 2013.
} 
Portanto, a resposta para o segundo questionamento apresentado no final da primeira parte remete a uma relação de custo/benefício entre as penalidades (pecuniárias e criminais) e os ganhos (não necessariamente monetários). A análise de custo/benefício, contudo, deve ser ponderada. A imposição de crime tributário não obsta a cobrança do tributo devido e da penalidade correspondente. Visando responder a segunda pergunta do final da primeira parte, conclui-se que as penalidades tributárias, mesmo as de caráter criminal, podem não ser suficientes para inibir comportamento ilegal do contribuinte.

Considerando uma Administração Tributária eficiente aquela que, em sua forma de atuação, atende a finalidade do interesse público escolhida pelo legislador em melhor arrecadar recursos tributários tomando formas menos custosas e prováveis de ocorrer. Sendo essa forma concretizada pela transferência de custos administrativos para o contribuinte, da qual o lançamento por homologação é espécie, embora atenda critério de eficiência referente ao seu aspecto quantitativo, não garante o cumprimento da legislação. Surge o questionamento da terceira e última parte do trabalho, bem como objetivo geral da pesquisa: como construir um ideal de Administração Tributária eficiente que induza o contribuinte a respeitar a legislação tributária quando do lançamento por homologação? Trata-se de resposta que se busca na terceira parte do trabalho.

\section{NOVO IDEAL DE ADMINISTRAÇÃO TRIBUTÁRIA EFICIENTE PELO CRITÉRIO DA CERTEZA E TAX COMPLIANCE}

O lançamento por homologação é medida que uma Administração Tributária eficiente utiliza para diminuir seus custos administrativos em relação à fiscalização, arrecadação e cobrança de tributos. Trata-se de transferência para o contribuinte dos custos por esses atos necessários ao recebimento de recursos tributários.

No aspecto de eficiência analisado na primeira parte deste trabalho, percebe-se ser medida focada mais no aspecto quantitativo e menos no aspecto probabilístico de certeza de promoção do fim. Afirmou-se na segunda parte que o lançamento por homologação onera o contribuinte, havendo situações que desencadearão opção pelo descumprimento da legislação tributária.

Parece que o problema se encontra na maior preocupação da transferência do custo administrativo e na pouca importância dada ao aspecto probabilístico da certeza da atuação 

ADMINISTRAÇÃO TRIBUTÁRIA EFICIENTE

eficiente. O lançamento por homologação, enquanto diminui os custos administrativos de arrecadação, também confia à vontade do contribuinte o cumprimento da legislação tributária. Em vistas a um ideal de Administração Tributária eficiente, resta questionar como, através do lançamento por homologação, pode ser induzido o cumprimento da legislação tributária?

0 enfoque para resposta a esta pergunta é também pela maior certeza que o meio irá realizar o fim buscado, e não apenas pelo menor custo. Mesmo que se considere que o lançamento por homologação irá cumprir minimamente o fim que se promove (arrecadação tributária), o dever de eficiência requer que a escolha do administrador seja a que promova de forma satisfatória o fim escolhido pelo legislador ${ }^{42}$.

Concluiu-se até o momento que o lançamento por homologação atende satisfatoriamente o primeiro requisito, mas não o segundo. A opção, portanto, é a construção de um ideal que tenha como objetivo mais certeza no cumprimento da legislação tributária no caso dos lançamentos por homologação.

Trata-se de analisar a relação entre o contribuinte e o Estado, de forma que este estimule o cumprimento das obrigações tributárias daquele. Internacionalmente, este fenômeno é denominado de tax compliance. A relação de confiança do contribuinte e sua visão como cliente da Administração Tributária (amistosidade fiscal), e não como possível infrator, é tema de diversas pesquisas de cunho empírico que intentam responder o motivo dos contribuintes pagarem tributos ${ }^{43}$. A consequência desses estudos implica também no interesse em como induzir o contribuinte a pagar seus tributos.

A experiência internacional demonstra que não existe uma receita política unitária que introduzida resultará necessariamente em uma Administração Tributária eficiente, ou no cumprimento espontâneo da legislação tributária. Diferentes países possuem diferentes níveis de tax compliance, refletindo não apenas na Administração Tributária, mas também na atitude dos contribuintes frente à tributação. Em geral, a percepção dos níveis de evasão tributária, de justiça da tributação, de complexidade e estabilidade do sistema tributário, da forma que a

\footnotetext{
42 MOREIRA NETO, Diogo de Figueiredo. Legitimidade e Discricionariedade: novas reflexões sobre os limites e controle da discricionariedade. 3. ed. Rio de Janeiro: Forense, 1998.

${ }^{43}$ MACIEL, Everardo. Considerações Finais. Trabalho apresentado na $45^{\mathrm{a}}$ Assembleia Geral do CIAT (Centro Interamericano de Administraciones Tributarias). Equador, abr. 2011. Disponível em: $<$ http:// webdms.ciat.org/action.php?kt_path_info=ktcore.actions.document.view\&fDocumentld=6097>. Acesso em: 16 dez. 2016. E, também: CHRISTOPOULOS, Basile Georges Campos; BASTOS, Frederico Silva. Administração Tributária Eficiente, Democracia e Desenvolvimento: experiências internacionais sobre índice de transparência fiscal e sua utilidade para o Brasil. Revista Discente DIREITO GV - redGV, v. 1, n. 2, p. 1-30, 2012.
} 
arrecadação é aplicada, e a legitimidade do Governo influenciam na atitude dos contribuintes em cumprir a lei tributária. A política específica de cada Governo, ao influenciar em um desses critérios, influencia também o comportamento dos contribuintes ${ }^{44}$.

Algumas proposições, apesar das diferenças estruturais dos sistemas tributários dos Estados internacionais, podem induzir ao cumprimento espontâneo da legislação tributária. A consideração dos contribuintes como clientes, e não como infratores em potencial, provendo informações sobre as obrigações acessórias, informando as vantagens de manterem seus cadastros atualizados, etc. Ou a simplificação dos meios de cobrança, por exemplo, eliminando a obrigação de apresentar informações desnecessárias e uniformizando a documentação a ser declarada $^{45}$.

Podem ser adotadas as proposições apresentadas ao lançamento por homologação. A quantidade de informações a serem apresentadas pelos contribuintes, a quantidade de dados a serem considerados para apuração tributária, a insegurança jurídica pela jurisprudência administrativa tributária, a instabilidade institucional do País e outros fatores, tornam a função de apurar o crédito tributário tarefa custosa. Relatório anual apresenta, em 2016, cerca de 2.038 (duas mil e trinta e oito) horas gastas por ano para o pagamento de tributos ${ }^{46}$. Ou seja, seriam necessários 85 (oitenta e cinco) dias integrais para que o contribuinte cumprisse todas as obrigações tributárias e pagamentos dos tributos brasileiros. A simplificação das obrigações acessórias relacionadas ao lançamento por homologação é medida que torna mais provável seu cumprimento.

O contribuinte, deparado com a simplificação do sistema tributário e diminuição de custos para se adequar a legislação, perceberá maior vantagem em se manter regularizado. Também, o contato direto do contribuinte com a Administração Tributária, dirimindo dúvidas gerais, respondendo processos de consulta e mantendo uma jurisprudência administrativa lógica e uniforme, resulta em confiança e segurança na Administração Tributária. A consequência é a indução ao cumprimento da legislação tributária.

Portanto, respondendo a problemática da pesquisa: é possível garantir o maior cumprimento da legislação tributária por parte do contribuinte nos casos de lançamento por homologação desde que um ideal de Administração Tributária, regulado pelo princípio da juridicidade administrativa, foque não apenas em seu aspecto quantitativo (transferência dos

\footnotetext{
${ }^{44}$ BIRD, Richard. Smart Tax Administration. The World Bank, n. 36, 2010.

${ }^{45}$ BIRD, Richard. Smart Tax Administration. The World Bank, n. 36, 2010.

${ }^{46}$ WORLD BANK. Doing Business 2017: equal opportunity for all. Washington: World Bank Group, 2016.
} 
custos administrativos), mas também em seu aspecto probabilístico (certeza). Para tanto, se impõe a construção de um novo modelo de Administração Tributária. A contemplação da confiança do contribuinte, tratando-o como cliente e não infrator, e a simplificação da legislação tributária se invocam para o cumprimento deste fim.

\section{CONCLUSÃO}

Buscou-se construir um ideal da Administração Tributária, pautada por uma eficiência regulada pela juridicidade e com bases em menos custos e mais certeza na arrecadação. Isso pelo problema da majoração dos custos dos contribuintes, consequência da transferência da Administração Tributária, no caso do lançamento por homologação. Novos custos induzem o contribuinte a descumprir a legislação tributária. Portanto, uma Administração Tributária eficiente deve focar também na construção da confiança do contribuinte, induzindo-o ao cumprimento espontâneo da legislação tributária.

$\mathrm{Na}$ primeira parte, defendeu-se conceito de eficiência pautado pela juridicidade. Deve atender uma das finalidades do interesse público escolhido pelo legislador, com, pelo menos, maior certeza e menos custos na atuação. No caso da Administração Tributária, a finalidade é a arrecadação. Percebeu-se que uma Administração Tributária eficiente busca praticar atos com conteúdo que visem maior certeza na arrecadação e menos custos administrativos. Uma das formas de diminuir os custos administrativos é através de medidas de transferência de custos para o contribuinte. Estas oneram os custos normais do contribuinte, devido à criação de novo custo de conformidade para adequação à legislação. A consequência é o desincentivo para o cumprimento da legislação tributária. Logo, conclui-se que a imputação do lançamento por homologação é espécie de transferência de custos administrativos que onera o contribuinte e desincentiva o cumprimento da legislação.

Na segunda, investigou-se a doutrina sobre a indução tributária. Notou-se a majoração dos custos, devido à imputação do lançamento por homologação, desestimulando o cumprimento da legislação tributária. O ônus pode ser tal que o contribuinte seja induzido, em análise de custo/benefício, a optar pelo descumprimento da legislação. Concluiu-se que nem mesmo a imputação de penalidades pecuniárias e criminais posteriores pode garantir o cumprimento da legislação tributária. Mesmo com as penalidades, o contribuinte ainda pode verificar mais vantagens em descumpri-la. 
Em um terceiro momento, buscou-se construir proposições práticas para o ideal de Administração Tributária eficiente. Com base no conceito de eficiência por menos custos e mais certeza na arrecadação, notou-se que o problema do não cumprimento da legislação nos casos de lançamento por homologação está no foco da Administração Tributária - mais na diminuição de custos do que na certeza da arrecadação. Conclui-se que a atuação eficiente deve tomar como solução a confiança do contribuinte na Administração Tributária. Para tanto, apresentaram-se duas proposições de pesquisa internacional sobre tax compliance. Ambas aplicam-se ao lançamento por homologação. A primeira, sobre a simplificação da tributação. A segunda, sobre tratamento do contribuinte como cliente (e não como infrator). Estas visam garantir maior confiança na Administração Tributária, o que induz ao cumprimento da legislação e maior certeza na arrecadação.

Por fim, respondendo ao questionamento da pesquisa, conclui-se ser possível garantir o maior cumprimento da legislação tributária por parte do contribuinte nos casos de lançamento por homologação. A forma proposta é a adoção de um ideal de Administração Tributária eficiente, pautada pela juridicidade. Focada na diminuição de custos e também na maior certeza da arrecadação. Para tanto, propõe-se a construção de melhor relação de confiança entre a Administração Tributária e o contribuinte. Esta confiança induz ao cumprimento espontâneo da legislação. Como consequência, maior certeza na arrecadação.

Para efetivar a proposta, apresenta-se a possibilidade de adoção, por uma Administração Tributária eficiente, de duas medidas que aumentem a confiança do contribuinte em sua atuação. A primeira, a simplificação da tributação, pois com a diminuição de custos para se adequar a legislação, o contribuinte perceberá maior vantagem em se manter regularizado. A segunda, no tratamento dos contribuintes como clientes, através, por exemplo, da resolução de dúvidas, procedimentos de consulta e mantendo uma jurisprudência administrativa lógica e uniforme. Conclui-se que embora estas medidas não sejam as únicas possíveis, sua adoção auxilia na construção da confiança entre o contribuinte e a Administração Tributária. Esta atenção à confiança induz o contribuinte a cumprir suas obrigações tributárias. Garante, portanto, o maior cumprimento da legislação tributária. 

ADMINISTRAÇÃO TRIBUTÁRIA EFICIENTE

\section{REFERÊNCIAS}

AMARAL, Antônio Carlos Cintra do. O princípio da eficiência no direito administrativo. Revista Eletrônica sobre a Reforma do Estado, Salvador, n. 5, mar./abr./maio 2006. Disponível em: <http: / / www.direitodoestado.com/revista/RERE-5-MAR\%C70-2006-CARLOS\%20CINTRA.pdf>. Acesso em: 10 jun. 2017.

AVILA, Humberto. Moralidade, Razoabilidade e Eficiência na Atividade Administrativa. Revista Eletrônica de Direito do Estado, Salvador, Instituto de Direito Público da Bahia, n. 4, out./nov./dez. 2005. Disponível em: <http://www.direitodoestado.com.br/artigo/humbertoavila/moralidade-razoabilidade-e-eficiencia-na-atividade-administrativa>. Acesso em: 23 nov. 2016.

BARROSO, Luís Roberto. Interpretação e Aplicação da Constituição. 5. ed. São Paulo: Saraiva, 2003.

BECKER, Alfredo Augusto. Teoria Geral do Direito Tributário. 5. ed. São Paulo: Noeses, 2010.

BERTOLUCCI, Aldo Vincenzo. Uma contribuição ao estudo da incidência dos custos de conformidade às leis e disposições tributárias: um panorama mundial e pesquisa dos custos das companhias de capital aberto no Brasil. São Paulo: USP, 2001. Dissertação (Mestrado) Faculdade de Economia e Administração, Universidade de São Paulo, São Paulo, 2001.

BINENBOJM, Gustavo. Uma Teoria do Direito Administrativo. 2. ed. Rio de Janeiro: Renovar, 2008.

BIRD, Richard. Smart Tax Administration. The World Bank, n. 36, 2010.

BITTENCOURT, Cezar Roberto; MONTEIRO, Luciana de Oliveira. Crimes Contra Ordem Tributária. São Paulo: Saraiva, 2013.

BOBBIO, Norberto. Teoria da Norma Jurídica. Barueri, SP: Edipro, 2001.

BOBBIO, Norberto. Da Estrutura à Função: novos estudos de teoria do Direito. Tradução de Daniela Beccaccia Versiani. Barueri, SP: Manole, 2007.

BRANDÃO, Renata Figueirêdo. Incentivo Fiscal Ambiental: parâmetros e limites para sua instituição à luz da Constituição Federal de 1988. São Paulo: USP, 2013. Tese (Doutorado) Faculdade de Direito da Universidade de São Paulo, São Paulo, 2013.

BRASIL. Constituição Federal. República Federativa do Brasil, Brasília, 5 out. 1988. Disponível em: <http://www.planalto.gov.br/ccivil_03/constituicao/constituicao.htm>. Acesso em: 10 jun. 2017.

BRASIL. Lei Complementar $n^{\circ} 118$, de 9 de fevereiro de 2005. Altera e acrescenta dispositivos à Lei no 5.172, de 25 de outubro de 1966 - Código Tributário Nacional, e dispõe sobre a 

ADMINISTRAÇÃO TRIBUTÁRIA EFICIENTE

interpretação do inciso I do art. 168 da mesma Lei. Diário Oficial da República Federativa do Brasil, Brasília, 9 fev. 2005. Disponível em:

<http://www.planalto.gov.br/ccivil_03/leis/LCP/Lcp118.htm>. Acesso em: 23 nov. 2016.

BRASIL. Lei $n^{\circ}$ 5.172, de 25 de outubro de 1966. Dispõe sobre o Sistema Tributário Nacional e institui normas gerais de direito tributário aplicáveis à União, Estados e Municípios. Diário Oficial da República Federativa do Brasil, Brasília, 27 out. 1966. Disponível em: <http://www.planalto.gov.br/ccivil_03/leis/L5172Compilado.htm>. Acesso em: 23 nov. 2016.

CHRISTOPOULOS, Basile Georges Campos; BASTOS, Frederico Silva. Administração Tributária Eficiente, Democracia e Desenvolvimento: experiências internacionais sobre índice de transparência fiscal e sua utilidade para o Brasil. Revista Discente DIREITO GV - redGV, v. 1, n. 2, p. 1-30, 2012.

COSTÓDIO FILHO, Ubirajará. A Emenda Constitucional n. ${ }^{\circ}$ 19/98 e o princípio da eficiência na Administração Pública. Revista de Direito Constitucional e Internacional, Cadernos de Direito Constitucional e Ciência Política, São Paulo, v. 27, p. 209-217, abr./jun. 1999.

FALCÃO, Amílcar de Araújo. Fato Gerador da Obrigação Tributária. 6. ed. Rio de Janeiro: Forense, 1997.

FONSECA, João Bosco Leopoldino da. Direito Econômico. 6. ed. Rio de Janeiro: Forense, 2010.

FREITAS, Juarez. Discricionariedade Administrativa e o Direito Fundamental à Boa Administração Pública. São Paulo: Malheiros, 2007.

GRAU, Eros Roberto. A ordem econômica na Constituição de 1988: interpretação e crítica. 12. ed. São Paulo: Malheiros, 2007.

LIMA, Leandro Manoel Matias de. A aplicação do dever de eficiência à Administração Pública Tributária e sua relação com a Moral Tributária dos contribuintes. Revista Digital de Direito Administrativo, v. 2, n. 1, p. 273-292, 2015.

MACIEL, Everardo. Considerações Finais. Trabalho apresentado na $45^{\mathrm{a}}$ Assembleia Geral do CIAT (Centro Interamericano de Administraciones Tributarias). Equador, abr. 2011. Disponível em: <http://webdms.ciat.org/action.php?kt_path_info=ktcore.actions.document.view\&fDocumentld =6097>. Acesso em: $16 \mathrm{dez} .2016$.

MEIRELLES, Hely L. Direito Administrativo Brasileiro. 36. ed. São Paulo: Malheiros, 2010.

MELLO, Celso Antônio Bandeira de. Discricionariedade e Controle Jurisidicional. São Paulo: Malheiros, 1998.

MIRAGEM, Bruno. A nova Administração Pública e o direito administrativo. São Paulo: Revista dos Tribunais, 2011.

MODESTO, Paulo. Notas para um Debate sobre o Princípio Constitucional da Eficiência. Revista Interesse Público, São Paulo, Ed. Notadez, n. 7, p. 65-75, 2000. 

ADMINISTRAÇÃO TRIBUTÁRIA EFICIENTE

MONCADA, Luis S. Cabral de. Direito Econômico: revista e actualizada. 2. ed. Coimbra: Coimbra, 1988.

MORAIS, Dalton Santos. Os custos da atividade administrativa e o princípio da eficiência. Revista dos Tribunais, v. 837, p. 79-105, jul. 2005.

MOREIRA NETO, Diogo de Figueiredo. Legitimidade e Discricionariedade: novas reflexões sobre os limites e controle da discricionariedade. 3. ed. Rio de Janeiro: Forense, 1998.

MOREIRA NETO, Diogo de Figueiredo Moreira; GARCIA, Flavio Amaral. Revista Eletrônica de Direito Administrativo Econômico (REDAE), Salvador, Instituto Brasileiro de Direito Público, n. 28, nov./dez./jan. 2011/2012. Disponível em:

<http: / / www.direitodoestado.com/revista/REDAE-28-NOVEMBRO-2011DIOGO-FIGUEIREDOFLAVIO-GARCIA.pdf>. Acesso em: 16 dez. 2016.

PLUTARCO, Hugo Mendes; GICO Jr., Ivo Teixeira; VALADÃO, Marcos Aurélio Pereira. O Custo Social das Obrigações Tributárias Acessórias. Economic Analysis of Law Review, v. 3, n. 2, p. 338-353, 2012.

SCHOUERI, Luis Eduardo. Normas Tributárias Indutoras e Intervenção Econômica. Rio de Janeiro: Forense, 2005.

VALENTE, Christiano Mendes Wolney. Denúncia espontânea: uma análise econômica da jurisprudência do STJ. Revista Fórum de Direito Tributário, Belo Horizonte, v. 13, n. 74, p. 81 . 100, mar. 2015.

WORLD BANK. Doing Business 2017: equal opportunity for all. Washington: World Bank Group, 2016.

\section{COMO FAZER A REFERÊNCIA DO ARTIGO (ABNT):}

MENDONÇA, Maria Lírida Calou de Araújo e; SILVA FILHO, Arnaldo Coelho da. A indução tributária como meio de construção de uma administração tributária eficiente. Revista Eletrônica do Curso de Direito da UFSM, Santa Maria, RS, v. 12, n. 3, p. 816-836, dez. 2017. ISSN 1981-3694. Disponível em: <https://periodicos.ufsm.br/revistadireito/article/view/25690>. Acesso em: dia mês. ano. doi: http://dx.doi.org/10.5902/1981369425690. 